\title{
Contextual control of Pavlovian feature-positive and feature-negative discriminations
}

\author{
SADAHIKO NAKAJIMA \\ Keio University, Tokyo, Japan
}

\begin{abstract}
Three pigeons were trained with a Pavlovian serial feature-positive (F-P) discrimination task in a light context, in which the houselight was on, and with a Pavlovian serial feature-negative (F-N) discrimination task in a dark context, in which the houselight was off. Three other pigeons were trained with the F-P task in the dark context and the F-N task in the light context. These two contextual conditions were changed randomly trial by trial. The former birds learned the tasks within 60 sessions, by responding exclusively to the target keylight after the feature tone in the light context and by responding exclusively to the target not preceded by the feature in the dark context. Two of the latter birds required separate training of the F-P and the F-N tasks to acquire the discrimination: responding exclusively to the target after the feature in the dark context and responding exclusively to the target not preceded by the feature in the light context. The third bird, however, failed to learn the discrimination even with separate training. These results indicate that the four-term contingency (the context-feature-target-food relationship) controlled the birds' behavior in the Pavlovian setting. The insertion of a temporal gap between the feature and the target impaired the F-N discrimination, although it had little effect on the F-P discrimination.
\end{abstract}

One of the most intriguing topics of recent Pavlovian conditioning studies is hierarchical control of the conditioned response. For example, in the Pavlovian serial feature-positive (F-P) discrimination paradigm, in which an unconditioned stimulus (US) follows a target stimulus (A) only when $\mathrm{A}$ is preceded by a feature stimulus (X), animals produce many conditioned responses (CRs) to $A$ after X, but few to A not preceded by X. Conversely, in the serial feature-negative (F-N) discrimination paradigm, the US follows $\mathrm{A}$ in A-alone trials but not in XA trials, and animals produce CRs exclusively to A not preceded by $\mathrm{X}$.

In these paradigms, it has been supposed that $\mathrm{X}$ modulates, or sets the occasion for, an A-US relation (Holland, 1983, 1985; Rescorla, 1985). That is, animals seem to learn the hierarchical structure of the X-(A-US) relation. Several investigators (e.g., Holland, 1983; Rescorla, $1985,1987)$ have pointed out the similarity of the function of the Pavlovian modulator or the occasion setter (X) and that of the discriminative stimulus $\left(S^{D}\right)$ in the operant discrimination in which the $S^{\mathbf{D}}$-(response-reinforcer) contingency is prepared. Some evidence supports this suggestion. Davidson, Aparicio, and Rescorla (1988) have shown that the Pavlovian facilitator, a kind of modulator

Portions of the data in this paper were presented at the $52 \mathrm{nd}$ annual meeting of the Japanese Society for Animal Psychology, Tokyo, July 1992. I thank Masaya Sato for encouraging this research. Thanks are due V. M. LoLordo and anonymous reviewers for valuable comments on the manuscript. Correspondence should be addressed to $S$. Nakajima, who is now at the Department of Psychology, Kwansei Gakuin University, Uegahara Nishinomiya, Hyogo 662, Japan. created by F-P discrimination training, and the operant $S^{D}$ are interchangeable: the facilitator augments operant responding and the $S^{D}$ augments responding to a conditioned stimulus trained as a target of the F-P discrimination (see also Colwill \& Rescorla, 1986). And Parker, Serdikoff, Kaminski, and Critchfield (1991) have obtained generalization gradients of facilitators that are functionally equivalent to those of operant $S^{D_{s}}$.

There have been many studies of Pavlovian modulation or occasion setting, but in all of them, three-term contingencies have been arranged: the feature signals the relationship of the target and the US. In operant discrimination, however, many studies have been done with four-term contingencies: conditional or instructional stimuli signal the relationship of $S^{\mathbf{D}}$, operant responding, and reinforcer (see Cumming \& Berryman, 1965; Mackay, 1991; and Sidman, 1986, for review and theoretical discussion). Moreover, some studies (e.g., Arnold, Grahame, \& Miller, 1991; Nevin \& Liebold, 1966) have been done with five-term contingencies.

The main purpose of the experiments reported here was to demonstrate a four-term contingency in Pavlovian conditioning. To establish this hierarchical stimulus control, I used the typical Pavlovian serial F-P and F-N discrimination preparations for pigeons as three-term contingencies: a diffuse auditory stimulus was the feature, a localized keylight was the target, and food was the US (Rescorla, 1985). Pecking to the target keylight was measured as a CR. The stimulus controlling these three-term contingencies was the contextual cue of the houselight. Several operant discrimination studies show that this cue is able to acquire the conditional stimulus function (e.g., Thomas \& Cur- 
ran, 1988; Thomas, Curran, \& Russell, 1988; Thomas \& Goldberg, 1985; Thomas, McKelvie, \& Mah, 1985; Thomas \& Schmidt, 1989).

\section{EXPERIMENT 1}

In Experiment 1, the birds received both the F-P and the F-N discrimination with the houselight condition as a contextual cue. Contingencies were arranged so that the contextual cue controlled which of these discrimination contingencies was in effect.

\section{Method}

Subjects. Six naive adult homing pigeons served as subjects. Their free-feeding body weight was established by unrestricted access to mixed grain. Then the weight of each bird was reduced to $80 \%$ of its free-feeding weight, and each was maintained at this level during the experiments by feeding it a small amount of mixed grain approximately $l \mathrm{~h}$ after each session. The birds were housed in individual home cages, where water and grit were continuously available.

Apparatus. The experimental chamber was a $30 \times 30 \times 30 \mathrm{~cm}$ cubicle with black plastic side and back walls, a black-painted aluminum front wall, a black plastic ceiling, and a mesh floor. The front wall contained a $2.8-\mathrm{cm}$ diameter response key mounted $17.5 \mathrm{~cm}$ above the floor. One 24-V 0.11-A miniature lamp with a colored plastic cover projected green light onto the key from the back. Both responding to the lit key and responding to the unlit key were detected by a microswitch attached to the key. Access to a solenoidoperated hopper containing hemp seeds was available through a $7-\mathrm{cm}$ wide $\times 6$-cm high opening located directly below the key. The bottom of the opening was $1 \mathrm{~cm}$ above the floor. When activated, the hopper was illuminated from above by a 24-V 0.11-A miniature lamp that presented white light. A 24-V 0.11-A white houselight was on the center of the ceiling. An electric buzzer (National EB2114) located $12 \mathrm{~cm}$ behind the front wall produced a $2.3-\mathrm{kHz}$ continuous tone. A speaker above the ceiling provided a continuous white noise during each session. The sound level of the tone was $85 \mathrm{~dB}$ (re Scale C) against the background $70-\mathrm{dB}$ white noise. The chamber was enclosed in a sound-attenuating shell situated in the experimental room. Experimental events were controlled and recorded by a Sony MSX $2+$ microcomputer located in the room, using programs written in Z-80 FORTH. During the sessions, all controlling equipment was silent and the experimenter was out of the room.

Procedure. All birds were tamed to eat grains from the experimenter's hand, and then the birds were given hopper training. The hopper training consisted of a few sessions that contained 45 presentations of the hemp seeds spaced a mean of $60 \mathrm{sec}$ (range: $30-90 \mathrm{sec}$ ) apart. The body weight of each bird was taken before and after each session, and the hopper training continued until each bird gained more than $5 \mathrm{~g}$ during the session. For some birds, complementary sessions in which the doors of the chamber and the shell were opened and the hemp seeds were presented by the experimenter's hand, and then by the hopper, were needed. The houselight was continuously illuminated, except during the food presentation.

The main part of the experiment consisted of discrimination training. Each session contained 48 trials separated by intervals with a mean of $60 \mathrm{sec}$ (range: $30-90 \mathrm{sec}$ ). Half the trials began with the 5 -sec feature tone, which was followed by the 5-sec target keylight; the other half began with the 5-sec target keylight alone. Whether the 5-sec access to hemp seeds followed the target keylight or not depended on the arranged contingencies.

The first intertrial interval (ITI) of each session began after a 30-sec dark (houselight-off) acclimation period. During the ITI, the houselight was continuously on or off, according to the arranged contingencies. The houselight condition of the given trial was the same as that of the preceding ITI. The houselight was always off during the 5-sec US presentation, but the houselight condition of that trial was continued for $5 \mathrm{sec}$ after the no-US trials. The next ITI began after this 5 -sec US or no-US period.

For half the birds (Al2, A32, and G12), each session contained four types of trials: $\mathrm{L}: \mathrm{G}-, \mathrm{L}: \mathrm{FG}+, \mathrm{D}: \mathrm{G}+, \mathrm{D}: \mathrm{FG}-$. On $\mathrm{L}: \mathrm{G}-$ trials, the houselight was on and the keylight was presented without the US. On L:FG + trials, the houselight was on and a sequence of the continuous tone and the keylight was followed by the US. On D:G+ trials, the houselight was off and the keylight was followed by the US. On D:FG - trials, the houselight was off and the sequence of the continuous tone and the keylight was presented without the US. These different trials were all presented once randomly within each of 12 successive blocks of four trials. New block sequences were generated session by session. The remaining birds (A11, F33, and H12) received the same training with the role of the houselight reversed: $\mathrm{D}: \mathrm{G}-, \mathrm{D}: \mathrm{FG}+, \mathrm{L}: \mathrm{G}+, \mathrm{L}: \mathrm{FG}-$. Thus, for Birds A12, $A 32$, and $G 12$, the F-P discrimination was conducted in the light context and the F-N discrimination was conducted in the dark context, and for birds A11, F33, and H12, the F-P discrimination was conducted in the dark context and the F-N discrimination was conducted in the light context. The training continued for 60 daily sessions.

Even after 60 sessions of such training, the latter birds (A11, F33, and H12) did not show contextual control of the F-P and the F-N discriminations. Thus, these birds received supplementary training in which the houselight condition was constant and either the F-P or the F-N contingency was arranged. (Two types of trials were presented twice randomly within each of 12 successive blocks of four trials.) Finally, the original contingencies consisting of four trial types were rearranged to establish good contextual control of the F-P and the F-N discriminations.

\section{Results and Discussion}

Figures 1 and 2 indicate each bird's rate of responding to the keylight on the four types of trials. The discrimination performance of the individual bird was assessed by using a discrimination index. Each index is of the form $[a /(a+b)] \times 100$, in which $a$ is the number of responses to the lit key on with-US (positive) trials and $b$ is the number of responses to the lit key on no-US (negative) trials. A value of $50 \%$ indicates random responding; $100 \%$ indicates perfect discrimination. The index was calculated session by session in both the F-P and the F-N discriminations. Figures 1 and 2 also show the indices for each bird.

In the first few sessions, the rate of responding was higher in the light context than in the dark context for all birds (the upper panel of each pair of the data presented in Figures 1 and 2). As the training went on, however, the rate on both kinds of positive trials ( $\mathrm{L}: \mathrm{FG}+$ and $\mathrm{D}: \mathrm{G}+$ ) increased and that on both kinds of negative trials (L:Gand $\mathrm{D}: \mathrm{FG}-$ ) decreased for $\mathrm{A} 12, \mathrm{~A} 32$, and $\mathrm{Gl} 2$, the birds for which the F-P contingency was arranged in the light context and the F-N contingency was arranged in the dark context. The lower panel of each pair in Figure 1 indicates that A12 and A32 acquired the F-P discrimination more rapidly than the F-N discrimination.

On the other hand, A11, F33, and H12, for which the F-P contingency was arranged in the dark context and the F-N contingency was arranged in the light context, had difficulty in acquiring these discriminations (Figure 2). Although A11 and H12 acquired the F-P task, the final per- 

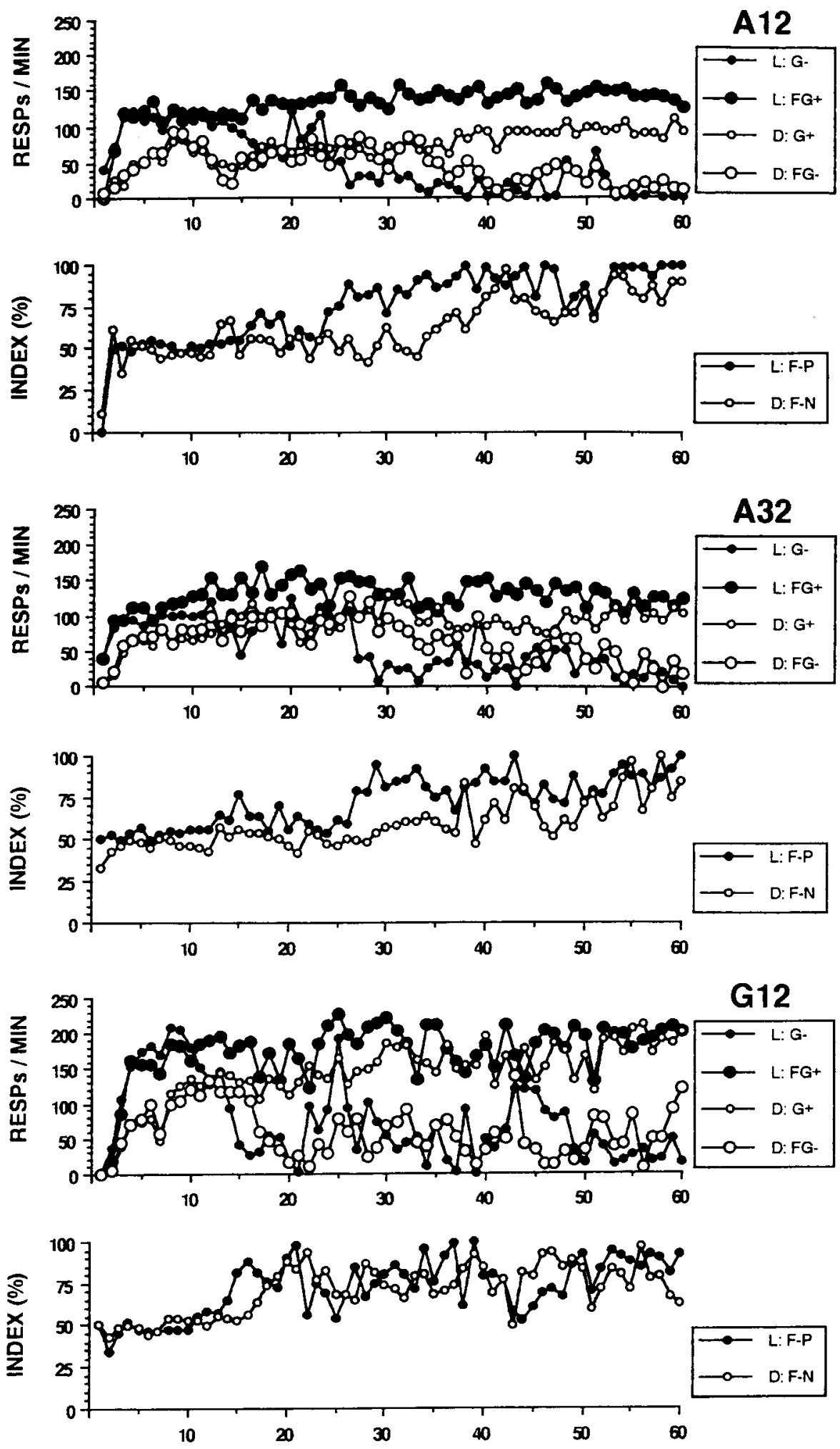

SESSIONS

Figure 1. Responses per minute to the green target keylight (the upper panels for each bird) and discrimination indices (the lower panels) of A12, A32, and G12. L, light (houselight-on) context; D, dark (houselight-off) context; $G$, responding to the green key presented alone; FG, responding to the green key presented after the feature tone; +, positive trials; - , negative trials; F-P, featurepositive discrimination; F-N, feature-negative discrimination. 

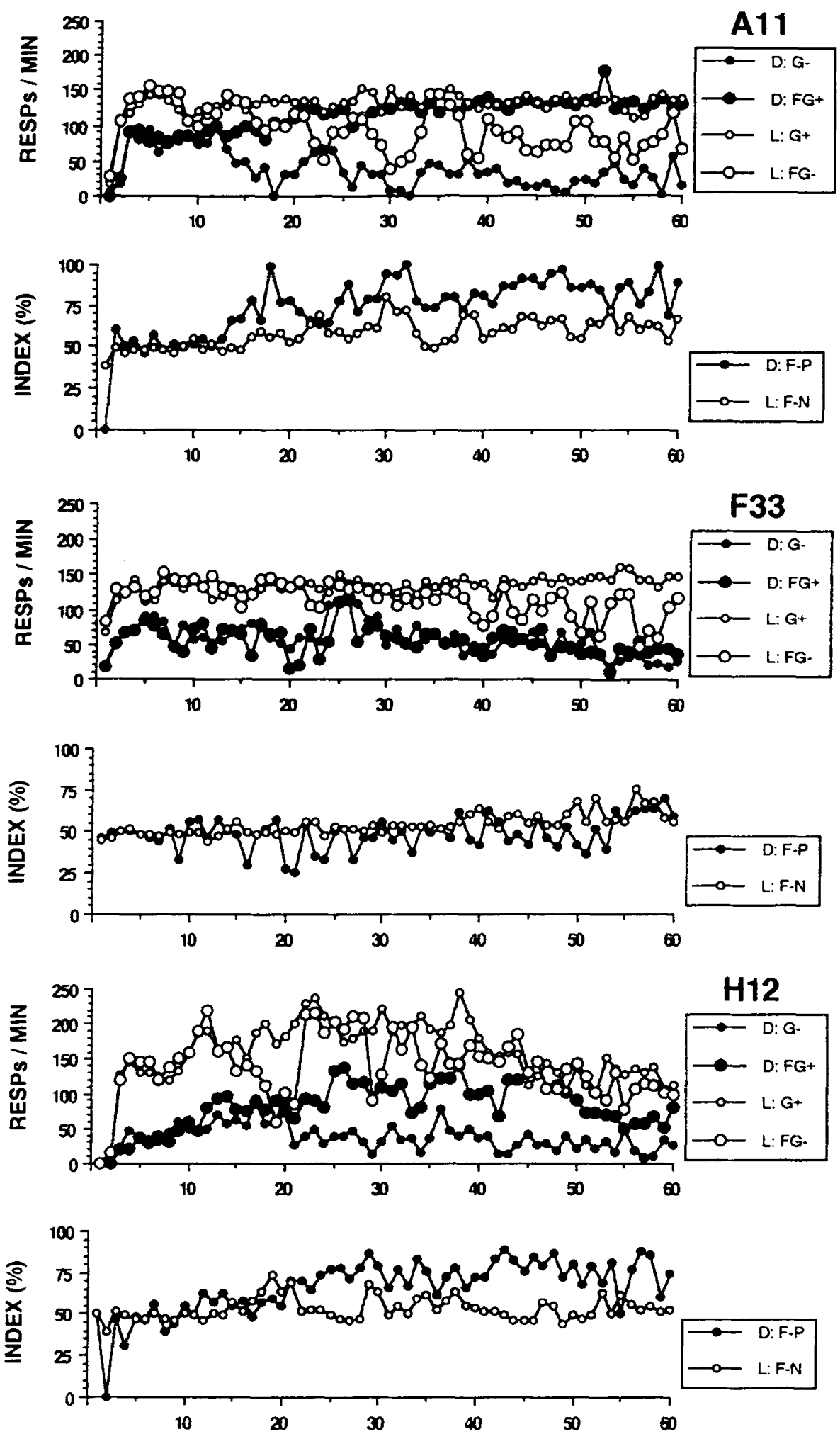

SESSIONS

Figure 2. Responses per minute to the green target keylight (the upper panels for each bird) and discrimination indices (the lower panels) of A11, F33, and H12. L, light (houselight-on) context; D, dark (houselight-off) context; G, responding to the green key presented alone; FG, responding to the green key presented after the feature tone; +, positive trials; -, negative trials; F-P, featurepositive discrimination; F-N, feature-negative discrimination. 
formances of these birds were poorer than those of the birds shown in Figure 1. A11 showed the slight discrimination in the F-N task, but $\mathrm{H} 12$ failed to acquire the F-N discrimination in 60 sessions. F33, the last bird of this group, showed almost no discrimination for 55 sessions, after which its levels of performance in both the F-P and F-N discriminations improved slightly.

For all birds, the responding to the unlit key was negligible during the feature presentation and in the ITI in the dark context. In the light context, all birds produced some pecks to the unlit key in the initial sessions. For all except A12, these pecks decreased in the later sessions: The rate of responding (pecks per minute) during the feature presentation averaged over the last 10 sessions was 2.7 for G12 and less than 1 for A32, A11, F33, and H12. A12, however, continued relatively high responding (36.4 pecks per minute, averaged over the last 10 sessions). The rate in the ITI averaged over the same sessions was less than 1 for all birds.

One might suggest that the birds used the responding during the feature presentation as an additional feature cue to responding when the target keylight was on in the light F-P context. It has been reported that pigeons spontaneously produce specific behaviors in the delayed matchingto-sample task as a cue to responding (Berryman, Cummining, \& Nevin, 1963; Blough, 1959). Indeed, the bird (A12) that produced many pecks to the unlit key is the bird that showed the best performance in the F-P discrimination. However, there are two difficulties with this possibility.

First, the rate of responding during the feature presentation was not correlated with the F-P discrimination performance. The correlation between these values calculated on the data from the last 30 sessions of $A 12$ was .21, and this value was not significant $(p>.20)$. Second, the other 2 birds (A32 and G12), which almost ceased responding to the unlit key, performed well in the F-P discrimination. For example, A32 discriminated perfectly in the F-P task of the last session with no pecks to the unlit key. Thus, the possibility that the birds used keypecking during the feature presentation as a cue to responding to the forthcoming target is implausible. However, this conclusion does not exclude the possibility that the birds engaged in other undetected behaviors during the feature presentation and used those behaviors as a cue to responding to the target.

In the supplementary training, A11 first received the F-N training in the light context. The houselight was always on during the session, except during the US presentation. A11 required 11 sessions to attain $90 \%$ performance in this discrimination and 4 sessions in the subsequent F-P training, in which the houselight was always off. In the first session of the second F-N discrimination the discrimination index was $88 \%$, and then the original contingencies, in which the context cued which of two discrimination tasks operated, were reinstated. In the initial two sessions of this treatment, performance on both discriminations was above the $80 \%$ level. The performance of A11 is shown in Figure 3.
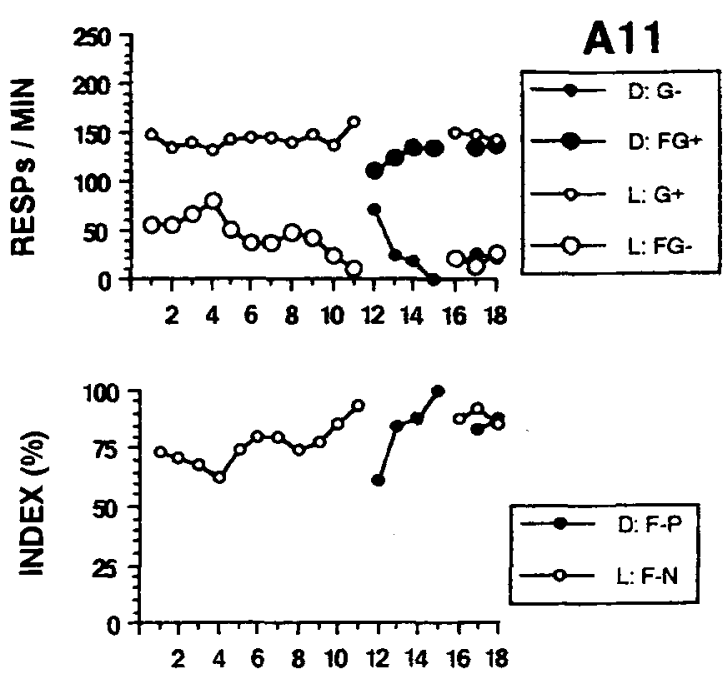

SES SION S

Figure 3. Responses per minute to the green target keylight (the upper panel) and discrimination indices (the lower panel) during the supplementary training of A11. L, light (houselight-on) context; $D$, dark (houselight-off) context; $G$, responding to the green key presented alone; FG, responding to the green key presented after the feature tone; +, positive trials; - , negative trials; F-P, featurepositive discrimination; $\mathbf{F - N}$, feature-negative discrimination.

Figure 4 indicates the performance of F33, which required 12 sessions in order to attain $90 \%$ performance in the first F-P discrimination. However, it failed to attain this level of performance for 38 sessions in the F-N discrimination. Its final discrimination performance hovered around $75 \%$. The best performance was $88 \%$ in the 39th session of this experiment. From the 61st session, the original contingencies were reinstated, and it took 10 sessions for the bird to reach the criterion in which the discrimination indices of the F-P and the F-N discriminations were both above $75 \%$ for 2 consecutive sessions.

Although $\mathrm{H} 12$ slowly acquired the F-N discrimination in the light context, $90 \%$ performance was never attained. Although this bird sometimes showed good performance, this discrimination was precarious. For example, H12's best performance was $85 \%$ on the 32nd session of F-N training, but the index for the next session was $63 \%$. It did not reach the $90 \%$ discrimination level for 60 sessions, and the index averaged over the final 5 sessions was $69 \%$. It also decreased its rate of responding: Responding to the keylight on the $\mathrm{L}: \mathrm{G}+$ trials changed from 132.2 per minute, averaged over the initial 5 sessions, to 35.6 per minute, averaged over the final 5 sessions; the corresponding value on the L:FG - trials changed from 126.3 to 17.3.

Responding to the unlit key was negligible for A11, F33, and $\mathrm{H} 12$ during this supplementary training.

The acquisition of contextual control of the F-P and the F-N discriminations in 2 birds (A11 and F33) after separate training on the two discriminations suggests that the 

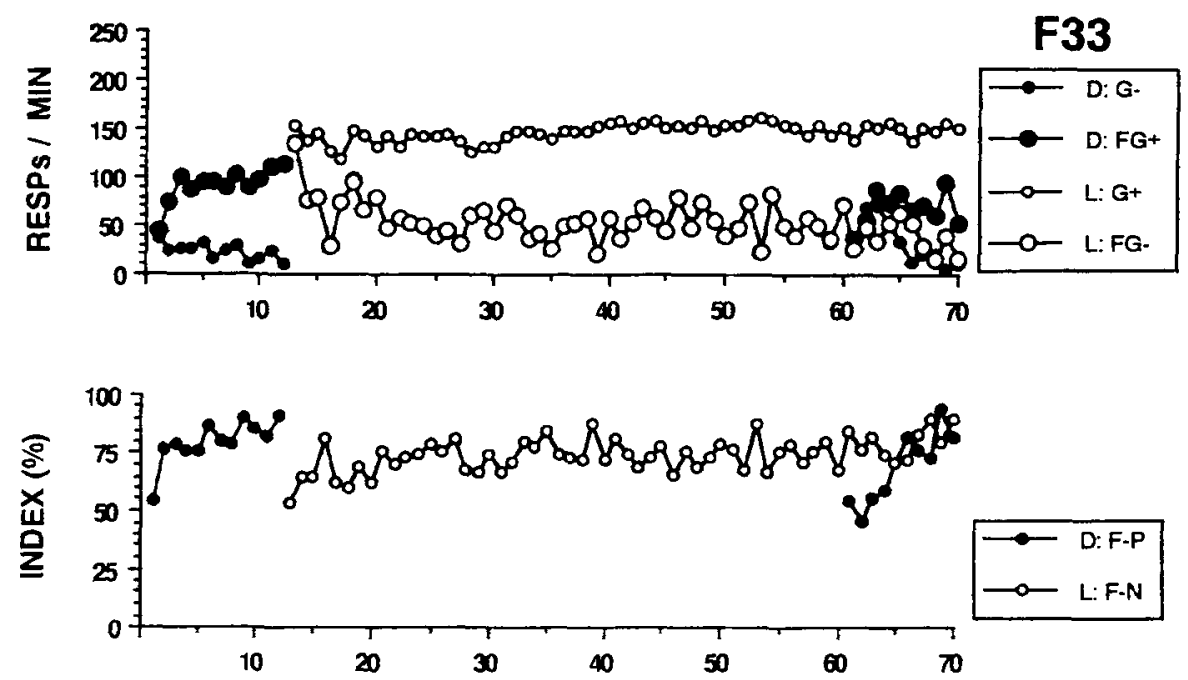

\section{SESSIONS}

Figure 4. Responses per minute to the green target keylight (the upper panel) and discrimination indices (the lower panel) during the supplementary training of F33. L, light (houselight-on) context; D, dark (houselight-off) context; G, responding to the green key presented alone; FG, responding to the green key presented after the feature tone; + , positive trials; - , negative trials; F-P, featurepositive discrimination; F-N, feature-negative discrimination.

within-session trial-by-trial alternation of contexts that had been used in the original training might have produced interference between trials and prevented the establishment of contextual control (see Thomas, Cook, \& Terrons, 1990; Thomas \& Goldberg, 1985). However, the 3rd bird (H12) failed even with separate training on the two discriminations, and the F-N discrimination of F33 was improved after the original within-session trial-bytrial alternation method was rearranged. Thus, the advantage of the separate method over the alternation method was not large enough to say that the former always produces better performance than the latter does.

\section{EXPERIMENT 2}

Looney, Cohen, Brady, and Cohen (1977) showed that gradual introduction of a temporal gap between the feature and the target caused deterioration of the performance of pigeons in a Pavlovian ambiguous discrimination task $(\mathrm{XA}+, \mathrm{YA}-, \mathrm{XB}-, \mathrm{YB}+)$, in which the US followed A preceded by $X$ but not by $Y$, and $B$ preceded by $Y$ but not by $X$. Nakajima (1992) indicated that the pigeons learned another serial ambiguous discrimination task, called a bidirectional occasion-setting task $(\mathrm{XA}+, \mathrm{A}-, \mathrm{XB}-$, $B+$ ), in which the feature preceded two kinds of targets on half the trials as a cue for discrimination, but that they had difficulty when a gap was inserted between the feature and the target. Rescorla (1985, 1991a, 1991b) and Parker et al. (1991), however, showed that pigeons easily learned the serial F-P discrimination with a 5-sec gap between the feature and the target. In Experiment 2, the effect of a gradually introduced gap on performance in the Pavlovian four-term discrimination was investigated.

\section{Method}

Subjects and Apparatus. A12, A32, G12, and A11 were trained in the same chamber as in Experiment 1.

Procedure. The training began on the day after Experiment 1 ended. The trial arrangement of each session was the same as that in Experiment 1, except that a temporal gap was inserted between the termination of the feature tone and the onset of the keylight target. At first, the inserted gap was $1 \mathrm{sec}$; it then increased by 1-sec steps. Each increment was introduced if the birds reached one of three criteria: (1) The discrimination indices of the F-P and the F-N discriminations were both above $75 \%$ for 2 consecutive sessions.

(2) These indices were both above $50 \%$ for 10 consecutive sessions.

(3) The bird received 30 sessions in the given gap-duration phase.

The first two were learning criteria. The maximum gap duration was $8 \mathrm{sec}$.

\section{Results and Discussion}

Although two learning criteria had been set up, visual inspection of the data showed that discrimination performance did not improve during each gap-duration phase. This impression was supported by statistical tests. Twotailed $M$ tests (Moore \& Wallis, 1943) applied both for the F-P and for the F-N tasks indicated that the trend of discrimination indices within each phase was not significant for any phase for any bird ( $p s>.298)$.

Thus, the discrimination index was averaged within each phase; it is shown in Figure 5 for individual birds. The numbers on the top of each panel indicate the number of sessions of each phase. For A11, the data of the 0 -sec phase were from the final two sessions of Experi- 


\section{A12}

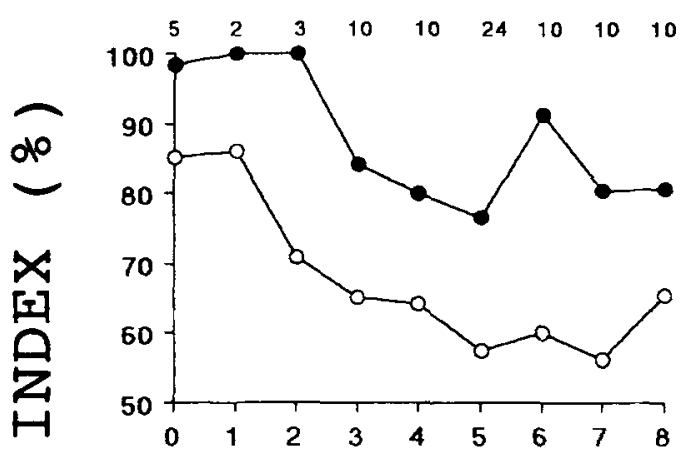

另

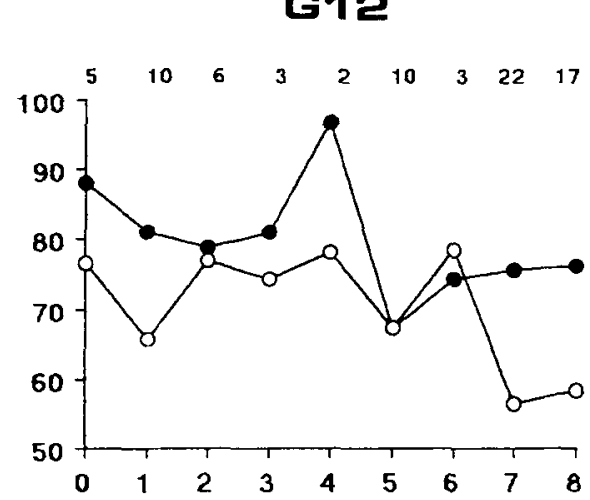

A32

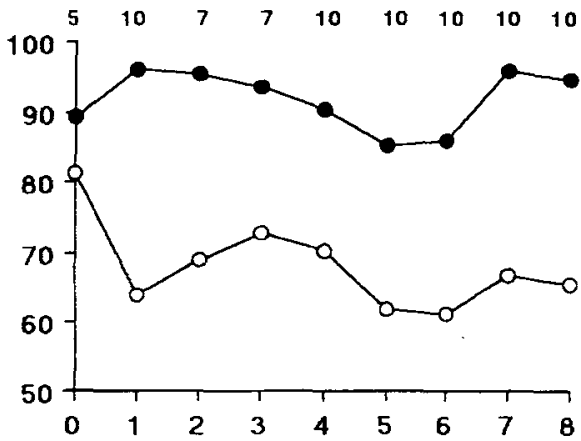

\section{TEMPORAL GAP (seconds)}

Figure 5. Discrimination indices as a function of a gradually introduced temporal gap between the feature and the target. The number of sessions of each gap phase is indicated in the uppermost part of each panel. F-P, featurepositive discrimination; F-N, feature-negative discrimination.

ment 1 , and for the remaining birds the data were from the final five sessions of that experiment. Except for that of A11, the performance during this phase was better in the F-P task than in the F-N task. With increments in the duration of the inserted gap, the performance of the F-N task deteriorated gradually. The performance of the F-P task, however, hovered around the $90 \%$ level for A32 and A11. Although that performance deteriorated gradually for $A 12$ and $\mathrm{G12}$, the indices of discrimination were still above $75 \%$ in the 8 -sec phase.

Table 1 shows the effects of the gap on the rate of responding to the keylights on the four types of trials. Each datum was based on the average of responding over all sessions of the given gap phase. For all birds except A32, the deterioration of the discriminative performance as a function of the gap duration was primarily the result of an increase in responding on the negative trials. For $\mathrm{A} 32$, on the contrary, a decrease in pecking rate on the positive trials contributed to the deterioration of the F-N discrimination as gap duration was increased.

In the dark context, the responding to the unlit key was negligible for all birds except A11. Although A11 produced almost no pecks during the feature presentation and in the ITI, its rate during the gap was an inverse U-shaped function of the gap duration. The average rates for each duration phase were $0.8(1 \mathrm{sec}), 1.9(2 \mathrm{sec}), 2.8(3 \mathrm{sec})$, $2.5(4 \mathrm{sec}), 2.4(5 \mathrm{sec}), 1.7(6 \mathrm{sec}), 0.0(7 \mathrm{sec})$, and 0.0 $(8 \mathrm{sec})$.

The responding to the unlit key in the light context of each bird is shown in Table 2 for each gap-duration phase. In general, the responding increased as the gap duration became long. However, this was not the case for A12; its 
Table 1

Average Rate of Responding to the Keylight (Responses per Minute) on Four Types of Trials in Experiment 2

\begin{tabular}{|c|c|c|c|c|c|c|c|c|c|c|}
\hline \multirow[b]{2}{*}{ Subject } & \multirow{2}{*}{$\begin{array}{l}\text { Trial } \\
\text { Type }\end{array}$} & \multicolumn{9}{|c|}{ Gap Duration } \\
\hline & & 0 & 1 & 2 & 3 & 4 & 5 & 6 & 7 & 8 \\
\hline A12 & $\begin{array}{l}\text { L:G- } \\
\text { L:FG+ } \\
\text { D:G+ } \\
\text { D:FG- }\end{array}$ & $\begin{array}{r}2.6 \\
139.2 \\
94.8 \\
16.4\end{array}$ & $\begin{array}{r}0.0 \\
144.5 \\
93.5 \\
16.0\end{array}$ & $\begin{array}{r}0.0 \\
157.7 \\
101.0 \\
43.0\end{array}$ & $\begin{array}{r}29.6 \\
151.9 \\
102.4 \\
57.6\end{array}$ & $\begin{array}{r}41.7 \\
156.9 \\
97.3 \\
54.8\end{array}$ & $\begin{array}{r}48.7 \\
148.2 \\
92.4 \\
70.6\end{array}$ & $\begin{array}{r}15.2 \\
152.8 \\
97.1 \\
66.8\end{array}$ & $\begin{array}{r}43.6 \\
160.8 \\
94.0 \\
74.2\end{array}$ & $\begin{array}{r}43.2 \\
168.1 \\
95.5 \\
51.8\end{array}$ \\
\hline A 32 & $\begin{array}{l}\text { L:G- } \\
\text { L:FG+ } \\
\text { D:G+ } \\
\text { D:FG- }\end{array}$ & $\begin{array}{r}15.0 \\
121.4 \\
101.8 \\
26.0\end{array}$ & $\begin{array}{r}5.6 \\
132.2 \\
103.4 \\
59.7\end{array}$ & $\begin{array}{r}7.9 \\
157.0 \\
103.6 \\
48.4\end{array}$ & $\begin{array}{r}14.4 \\
183.6 \\
88.4 \\
33.7\end{array}$ & $\begin{array}{r}23.0 \\
177.1 \\
79.5 \\
34.2\end{array}$ & $\begin{array}{r}36.2 \\
185.1 \\
69.0 \\
43.4\end{array}$ & $\begin{array}{r}35.1 \\
195.5 \\
56.3 \\
36.0\end{array}$ & $\begin{array}{r}9.0 \\
190.9 \\
54.1 \\
27.8\end{array}$ & $\begin{array}{r}10.8 \\
175.9 \\
61.2 \\
32.9\end{array}$ \\
\hline G12 & $\begin{array}{l}\text { L:G- } \\
\text { L:FG+ } \\
\text { D:G+ } \\
\text { D:FG- }\end{array}$ & $\begin{array}{r}27.8 \\
199.2 \\
192.0 \\
63.4\end{array}$ & $\begin{array}{r}48.9 \\
198.8 \\
146.6 \\
77.8\end{array}$ & $\begin{array}{r}66.2 \\
246.3 \\
194.7 \\
61.7\end{array}$ & $\begin{array}{r}51.0 \\
219.3 \\
183.7 \\
62.7\end{array}$ & $\begin{array}{r}7.5 \\
244.0 \\
210.0 \\
59.0\end{array}$ & $\begin{array}{l}110.0 \\
218.5 \\
206.1 \\
108.7\end{array}$ & $\begin{array}{r}81.0 \\
224.7 \\
209.0 \\
57.7\end{array}$ & $\begin{array}{r}66.4 \\
189.9 \\
201.7 \\
158.6\end{array}$ & $\begin{array}{r}61.2 \\
188.9 \\
191.0 \\
140.5\end{array}$ \\
\hline A11 & $\begin{array}{l}\text { D:G- } \\
\text { D:FG + } \\
\text { L:G+ } \\
\text { L:FG- }\end{array}$ & $\begin{array}{r}23.5 \\
135.0 \\
145.0 \\
18.5\end{array}$ & $\begin{array}{r}16.7 \\
143.5 \\
141.7 \\
36.7\end{array}$ & $\begin{array}{r}8.9 \\
134.9 \\
138.6 \\
53.4\end{array}$ & $\begin{array}{r}5.0 \\
137.0 \\
135.7 \\
44.0\end{array}$ & $\begin{array}{r}2.5 \\
143.0 \\
138.5 \\
34.0\end{array}$ & $\begin{array}{r}7.6 \\
136.8 \\
141.4 \\
102.9\end{array}$ & $\begin{array}{r}8.7 \\
133.6 \\
139.6 \\
89.0\end{array}$ & $\begin{array}{r}19.2 \\
115.8 \\
138.9 \\
124.0\end{array}$ & $\begin{array}{r}12.1 \\
109.6 \\
147.6 \\
136.3\end{array}$ \\
\hline
\end{tabular}

Table 2

Average Rate of Responding to the Unlit Key (Responses per Minute) in the Light Context in Experiment 2

\begin{tabular}{|c|c|c|c|c|c|c|c|c|c|}
\hline \multirow[b]{2}{*}{ Subject } & \multirow[b]{2}{*}{ Period } & \multicolumn{8}{|c|}{ Gap Duration } \\
\hline & & 1 & 2 & 3 & 4 & 5 & 6 & 7 & 8 \\
\hline $\mathrm{A} 12$ & $\begin{array}{l}\text { feature } \\
\text { gap } \\
\text { ITI }\end{array}$ & $\begin{array}{r}33.0 \\
72.5 \\
0.5\end{array}$ & $\begin{array}{r}27.3 \\
76.7 \\
0.0\end{array}$ & $\begin{array}{r}22.3 \\
83.2 \\
1.0\end{array}$ & $\begin{array}{r}23.4 \\
91.0 \\
1.9\end{array}$ & $\begin{array}{r}20.8 \\
77.0 \\
1.8\end{array}$ & $\begin{array}{r}17.8 \\
91.8 \\
0.7\end{array}$ & $\begin{array}{r}11.5 \\
63.1 \\
0.5\end{array}$ & $\begin{array}{r}10.5 \\
38.1 \\
0.6\end{array}$ \\
\hline A32 & $\begin{array}{l}\text { feature } \\
\text { gap } \\
\text { ITI }\end{array}$ & $\begin{array}{l}1.4 \\
3.5 \\
0.4\end{array}$ & $\begin{array}{r}3.7 \\
25.4 \\
0.1\end{array}$ & $\begin{array}{r}10.0 \\
69.3 \\
0.8\end{array}$ & $\begin{array}{r}20.4 \\
77.9 \\
3.4\end{array}$ & $\begin{array}{r}16.2 \\
88.0 \\
2.4\end{array}$ & $\begin{array}{r}16.7 \\
96.0 \\
2.3\end{array}$ & $\begin{array}{r}10.8 \\
100.3 \\
0.3\end{array}$ & $\begin{array}{r}10.5 \\
97.4 \\
1.4\end{array}$ \\
\hline G12 & $\begin{array}{l}\text { feature } \\
\text { gap } \\
\text { ITI }\end{array}$ & $\begin{array}{r}4.7 \\
15.0 \\
0.1\end{array}$ & $\begin{array}{r}4.7 \\
13.8 \\
0.2\end{array}$ & $\begin{array}{r}5.0 \\
19.4 \\
0.3\end{array}$ & $\begin{array}{r}4.5 \\
28.1 \\
0.0\end{array}$ & $\begin{array}{r}4.6 \\
13.6 \\
0.7\end{array}$ & $\begin{array}{r}15.7 \\
35.6 \\
2.2\end{array}$ & $\begin{array}{r}22.5 \\
45.8 \\
4.5\end{array}$ & $\begin{array}{r}17.8 \\
42.6 \\
3.8\end{array}$ \\
\hline A11 & $\begin{array}{l}\text { feature } \\
\text { gap } \\
\text { ITI }\end{array}$ & $\begin{array}{l}0.7 \\
1.7 \\
0.6\end{array}$ & $\begin{array}{l}1.3 \\
1.3 \\
3.0\end{array}$ & $\begin{array}{l}2.0 \\
1.7 \\
1.0\end{array}$ & $\begin{array}{l}1.5 \\
3.1 \\
0.6\end{array}$ & $\begin{array}{l}0.1 \\
1.1 \\
0.2\end{array}$ & $\begin{array}{l}0.6 \\
0.4 \\
0.2 \\
\end{array}$ & $\begin{array}{r}17.6 \\
20.2 \\
9.4\end{array}$ & $\begin{array}{l}54.5 \\
61.7 \\
29.8\end{array}$ \\
\hline
\end{tabular}

Note-ITI, intertrial interval.

rate during the feature was a decreasing function of the gap duration, and both the rate during the gap and the rate in the ITI were inverse U-shaped functions of duration.

The responding during the gap might contribute to the good performance of the F-P discrimination with the long gap, but evidence does not support this possibility. First, the rate of responding during the gap in the F-P discrimination (the light context) of A12 was not a simple increasing function of the gap duration as described above. Second, for A11, the rate during the gap in the F-P discrimination (the dark context; not shown in Table 2) was also an inverse $\mathrm{U}$-shaped function of the gap duration. Furthermore, A11 showed very good performance in the 7-sec gap and 8-sec gap phases, in which the responding during the gap was almost zero. Finally, the rate of responding during the gap was very low in the other phases, and it is unlikely that responding at such a low rate contributed to good performance of the F-P discrimination by $\mathrm{A} 11$.

\section{EXPERIMENT 3}

In Experiment 2, the temporal gap gradually introduced between the feature and the target impaired the performance of the F-N discrimination, but the impairment on the F-P discrimination was not so large. This asymmetrical effect, however, was not statistically significant. Moreover, 3 of the 4 birds showed better performance at the no-gap phase in the F-P discrimination than in the F-N discrimination. Thus the impairment of the $\mathrm{F}-\mathrm{N}$ discrimination by the gap might be attributed to the poor performance of that subtask in general.

In Experiment 3, the effect of the gap on the performance of the F-P and F-N discriminations was tested again, but, this time, a single-session test was used for each gap duration in order to exclude an effect of long training of the given gap duration. This test was conducted after the F-N discrimination improved to show as good baseline performance as the F-P discrimination did. 


\section{Method}

Subjects and Apparatus. A12, A32, and G12, which had been used in Experiments 1 and 2, and F33, which had been used in Experiment 1, served as the subjects. The chamber was the same as in the previous experiments.

Procedure. For A12, A32, and G12, the original training began from the day after Experiment 2 ended, and it continued until they attained $75 \%$ performance in both F-P and F-N discriminations without the gap for two consecutive sessions. The number of sessions of this training were 5 for A12, 29 for A32, and 13 for G12. Then some variations of the procedure were introduced during the final 8 trials of the sessions. In the first variation, the color of the keylight was changed from green to red and the training continued for 7 sessions. Then the original training was reinstated for 2 or 3 sessions. In the second variation, the nature of the tone was changed from continuous to intermittent and training continued for 7 sessions. F33 also received these treatments after Experiment 1. These treatments were conducted for purposes unrelated to the present one and the results were too complex to discuss here. In any case, the birds received discrimination training, which was similar to the original training, for 16 or 17 sessions. And it is important to note that at the end of these sessions the F-N performance improved and was comparable to the F-P performance.

Then the original no-gap training was reinstated and continued until the birds attained the $75 \%$ criterion described above. When the given bird attained the criterion, that bird was tested on the next day. The test session was the same as that for the original training, except that the temporal gap was inserted between the termination of the feature tone and the onset of the keylight target. Then the original training was reinstated and continued until the bird satisfied the same criterion, and the second test was conducted. This routine was repeated until there were four tests. For all birds, the gap in the first test session was $8 \mathrm{sec}$; in the second, $3 \mathrm{sec}$; in the third, $1 \mathrm{sec}$; and in the fourth, $5 \mathrm{sec}$.

\section{Results and Discussion}

A12 and G12 completed the experiment with the minimum number of sessions of the original no-gap retraining: 2 sessions $\times 4$ times $=8$ sessions. A32 required 5 sessions to reattain the criterion after the 8-sec gap test session, and 4 sessions after the 1-sec gap test session. F33 required 4 sessions after the 8-sec gap test session.

Figure 6 shows the indices of the F-P and F-N discriminations as a function of the duration of the gap. Each point for the 0 -sec duration was the average of 8 criterion sessions of the original no-gap retraining. In the 0 -sec duration, the performance on the F-N discrimination was comparable to that on the F-P discrimination for all birds. With
A12

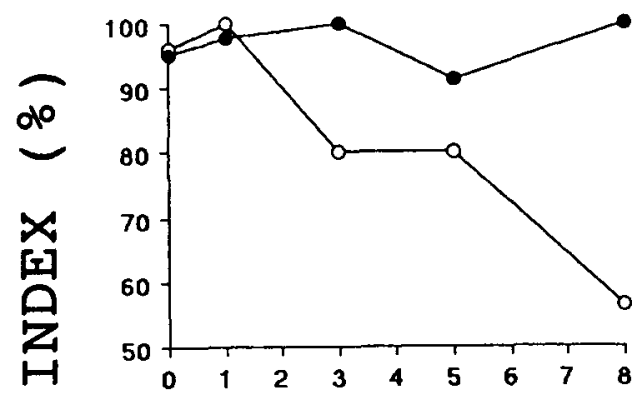

G12

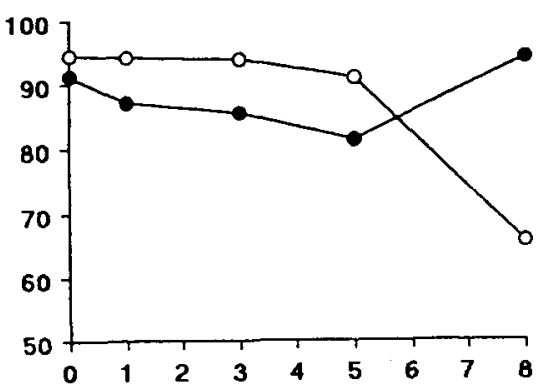

A 32

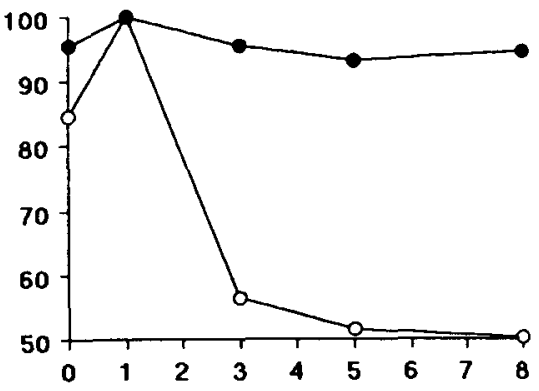

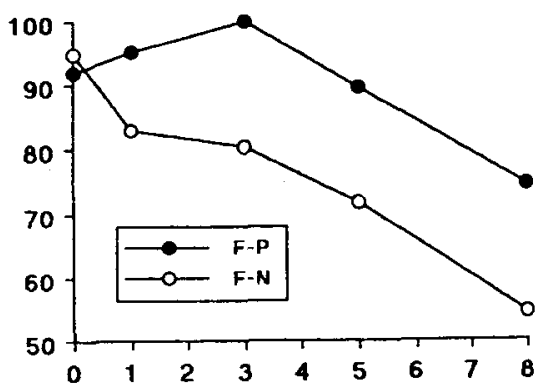

\section{TEMPORAL GAP (seconds)}

Figure 6. Discrimination indices as a function of a temporal gap between the feature and the target. F-P, feature-positive discrimination; F-N, feature-negative discrimination. 
increments of the inserted gap, however, the performance on the F-N discrimination deteriorated gradually. The performance on the F-P discrimination, on the contrary, was maintained over all gap durations, though F33 showed a small decrement in the 8-sec duration.

The asymmterical effect of the gap on the discriminations was supported by the results of an analysis of variance with two repeated measures (discriminations and durations) and four subject replications. This analysis showed that the main factor of durations $[F(4,12)=10.55, p<$ $.001]$ and the discriminations $\times$ durations interaction $[F(4,12)=6.60, p<.01]$ were significant. Follow-up tests on the interaction indicated that performance in the F-N discrimination changed significantly over durations $[F(4,15)=8.76, p<.001]$, but the performance in the F-P discrimination did not $[F(4,15)<1]$.

Table 3 shows the effect of the gap on the rate of responding to the target on four types of trials. For all birds, the deterioration of the discriminative performance as a function of the gap duration was primarily the result of an increase in responding on the negative trials.

In the dark context, responding to the unlit key was negligible. Responding to the unlit key in the light context for A12, A32, and G12 is shown in Table 4 for each gap duration. No systematic relationship between the number of responses and the gap duration was observed for these birds. F33 never pecked to the unlit key in the light context.

These results replicated the robustness of the F-P discrimination when a gap was inserted between the feature and the target. At the beginning of this experiment, the discrimination performance of the F-N task with no gap improved enough to reach the same level as that of the F-P task with no gap. This fact excludes the possibility that the asymmetrical effect of the gap should be attributed to the generally poor performance of the F-N discrimination.

Table 3

Rate of Responding to the Keylight (Responses per Minute) on Four Types of Trials in Experiment 3

\begin{tabular}{|c|c|c|c|c|c|c|}
\hline \multirow[b]{2}{*}{ Subject } & \multirow{2}{*}{$\begin{array}{l}\text { Trial } \\
\text { Type }\end{array}$} & \multicolumn{5}{|c|}{ Gap Duration } \\
\hline & & $0^{*}$ & 1 & 3 & 5 & 8 \\
\hline A12 & $\begin{array}{l}\text { L:G- } \\
\text { L:FG+ } \\
\text { D:G+ } \\
\text { D:FG- }\end{array}$ & $\begin{array}{r}7.0 \\
136.8 \\
66.6 \\
2.9\end{array}$ & $\begin{array}{r}3.0 \\
140.0 \\
57.0 \\
0.0\end{array}$ & $\begin{array}{r}0.0 \\
140.0 \\
52.0 \\
13.0\end{array}$ & $\begin{array}{r}15.0 \\
159.0 \\
60.0 \\
15.0\end{array}$ & $\begin{array}{r}0.0 \\
140.0 \\
71.0 \\
55.0\end{array}$ \\
\hline A32 & $\begin{array}{l}\mathrm{L}: \mathrm{G}- \\
\mathrm{L}: \mathrm{FG}+ \\
\mathrm{D}: \mathrm{G}+ \\
\mathrm{D}: \mathrm{FG}-\end{array}$ & $\begin{array}{r}7.1 \\
141.9 \\
49.1 \\
9.3\end{array}$ & $\begin{array}{r}0.0 \\
137.0 \\
39.0 \\
0.0\end{array}$ & $\begin{array}{r}7.0 \\
144.0 \\
57.0 \\
44.0\end{array}$ & $\begin{array}{r}11.0 \\
155.0 \\
60.0 \\
56.0\end{array}$ & $\begin{array}{r}9.0 \\
167.0 \\
58.0 \\
57.0\end{array}$ \\
\hline G12 & $\begin{array}{l}\text { L:G- } \\
\text { L:FG+ } \\
\text { D:G+ } \\
\text { D:FG- }\end{array}$ & $\begin{array}{r}23.6 \\
231.5 \\
169.5 \\
9.8\end{array}$ & $\begin{array}{r}33.0 \\
227.0 \\
175.0 \\
11.0\end{array}$ & $\begin{array}{r}37.0 \\
219.0 \\
167.0 \\
11.0\end{array}$ & $\begin{array}{r}53.0 \\
230.0 \\
189.0 \\
19.0\end{array}$ & $\begin{array}{r}13.0 \\
218.0 \\
171.0 \\
89.0\end{array}$ \\
\hline F33 & $\begin{array}{l}\mathrm{D}: \mathrm{G}- \\
\mathrm{D}: \mathrm{FG}+ \\
\mathrm{L}: \mathrm{G}+ \\
\mathrm{L}: \mathrm{FG}-\end{array}$ & $\begin{array}{r}6.3 \\
73.9 \\
151.8 \\
8.8\end{array}$ & $\begin{array}{r}3.0 \\
60.0 \\
153.0 \\
31.0\end{array}$ & $\begin{array}{r}0.0 \\
77.0 \\
152.0 \\
37.0\end{array}$ & $\begin{array}{r}7.0 \\
61.0 \\
146.0 \\
57.0\end{array}$ & $\begin{array}{r}20.0 \\
59.0 \\
159.0 \\
132.0\end{array}$ \\
\hline
\end{tabular}

*Average of 8 criterion sessions.
Table 4

Rate of Responding to the Unlit Key (Responses per Minute) in the Light Context in Experiment 3

\begin{tabular}{llrrrrr}
\hline & \multicolumn{7}{c}{ Gap Duration } \\
\cline { 2 - 7 } Subject & Period & $0^{*}$ & 1 & 3 & 5 & 8 \\
\hline A12 & feature & 13.5 & 4.0 & 5.0 & 13.0 & 17.0 \\
& gap & & 10.0 & 23.3 & 20.0 & 41.9 \\
& ITI & 0.2 & 0.0 & 0.0 & 0.0 & 0.6 \\
A32 & feature & 37.1 & 29.0 & 37.0 & 29.0 & 39.0 \\
& gap & & 75.0 & 86.7 & 78.0 & 88.1 \\
& ITI & 1.2 & 0.0 & 0.1 & 0.9 & 1.6 \\
G12 & feature & 3.3 & 14.0 & 3.0 & 6.0 & 5.0 \\
& gap & & 15.0 & 1.6 & 4.0 & 2.5 \\
& ITI & 0.1 & 1.1 & 0.2 & 1.0 & 0.0 \\
\hline
\end{tabular}

Note-ITI, intertrial interval. *Average of 8 criterion sessions.

The use of a single-session test excludes the effect of long training of the given gap duration. It is also noteworthy that F33 had never experienced the gap treatment of Experiment 2. Although it showed slight deterioration of the F-P discrimination in the 8-sec duration (the first gap session for this bird), the F-P performance was better than that on the F-N discrimination even at this duration.

\section{GENERAL DISCUSSION}

The behavior of pigeons was controlled by the fourterm contingency in Pavlovian conditioning. The contextual cues (on or off) of the houselight indicated whether the feature tone signaled that the target keylight would be followed by the food US (F-P discrimination contingency) or would not be followed by the food US (F-N discrimination contingency). That is, the context-featuretarget-US contingency operated in the experiments reported here, and the birds performed in an orderly way in this complex contingency.

The birds for which the light context indicated the F-P contingency and the dark context indicated the F-N contingency learned this complex arrangement, though the birds for which the former indicated the F-N contingency and the latter indicated the F-P contingency needed supplementary training to learn both the F-P and the F-N discriminations (Experiment 1). Looney and Griffin (1978), using a group design, showed that the Pavlovian serial F-P discrimination was acquired faster than the F-N discrimination. This superiority of the F-P discrimination was replicated in Experiment 1 on a within-subject basis: 4 of the 6 birds learned the F-P task faster than the F-N task.

The gradual introduction of the temporal gap between the feature and the target negatively affected the F-N discrimination for all 4 birds, but it had no effect on the F-P discrimination for 2 of the 4 birds (Experiment 2). This asymmetrical effect of the gap was also observed in the single-session test (Experiment 3). Recently, Nakajima (1993) showed that pigeons could learn the F-P discrimination, whether or not the 5-sec gap was inserted between the feature and the target. However, pigeons that were 
trained with two F-N discrimination tasks, one without the gap and the other with the 5-sec gap, learned only the discrimination without the gap. Experiments 2 and 3 thus replicated the asymmetrical effect of the inserted gap on the F-P and the F-N discriminations in the more complex arrangement.

This study demonstrated the complex control of behavior in Pavlovian conditioning with pigeons as subjects. It has been supposed that the birds solved the discrimination problem according to the hierarchical stimulus structure-that is, that the birds learned the context-(feature-(target-US)), structure. However, they could have attained successful performance with strategies other than this hierarchical one.

The most probable alternative is use of the unique cue or configuration (see, e.g., Bellingham \& Gillette, 1981; Bellingham, Gillette-Bellingham, \& Kehoe, 1985; Holland \& Block, 1983; Kehoe \& Gormezano, 1980; Pearce \& Wilson, 1990a, 1990b; Preston, Dickinson, \& Mackintosh, 1986; Rescorla, 1973; Rescorla, Grau, \& Durlach, 1985; Saavedra, 1975; Whitlow \& Wagner, 1972; Wilson \& Pearce, 1992). For example, the birds might perceive the target keylight after the feature tone in one context (the F-P context) as a configural stimulus and perceive the target not preceded by the feature in the other context (the F-N context) as the other configural stimulus. They could use these configural stimuli as a signal for the US. It was possible that they also perceived the target not preceded by the feature in the F-P context as the third configural stimulus and the target after the feature in the F$\mathrm{N}$ context as the fourth configural stimulus and used these cues as a signal for the absence of the US.

Another possibility is the use of the bidirectional occasion-setting strategy (Nakajima, 1992). The green keylight was used as a target in the experiments reported here, and I have treated this stimulus as identical in both the dark and the light contexts. However, the birds might perceive it as two different keylights in these different contexts, and the feature might signal that one of them will be followed by the US (positive occasion setting) and that the other keylight will not be followed by the US (negative occasion setting). Nakajima (1992) showed that pigeons can learn this kind of bidirectional occasionsetting task.

Although both configuration and bidirectional occasion setting seem good alternatives to the hierarchical strategy, the asymmetrical effect of the temporal gap shown in Experiments 2 and 3 made these alternatives implausible. This effect has also been demonstrated by Nakajima (1993), by using the typical Pavlovian serial F-P and F-N discrimination preparations in which it has been maintained that the birds use the modulating or occasion-setting strategy rather than configuration (e.g., Rescorla, 1985). The asymmetrical effect of the gap shown here suggests that the same mechanism is operating as in the typical F-P and the F-N discriminations. The asymmetrical effect of the gap also argues against bidirectional occasion setting, because Nakajima (1992) showed that in the bidirectional occasion-setting task the gap negatively affected the F-P discrimination $(\mathrm{XA}+, \mathrm{A}-$ ) and the $\mathrm{F}-\mathrm{N}$ discrimination $(\mathrm{XB}-, \mathrm{B}+)$ to the same extent.

Several other results also favor hierachical stimulus control over configuration and bidirectional occasion setting. The birds showed some discrimination even if the inserted gap was $8 \mathrm{sec}$. Configuration is implausible when the stimuli are separated by such a long unfilled gap (Arnold et al., 1991). Bidirectional occasion setting is also unlikely, for two reasons. First, all 6 birds used by Nakajima (1992) failed to show superiority of the F-P discrimination over the F-N discrimination in the acquisition of bidirectional occasion setting. However, as described before, 4 of the 6 birds used here showed clear F-P superiority. Thus the acquisition mechanism of the bidirectional occasionsetting task seems different from that of the task used here. Second, Thomas et al. (1985) demonstrated that a change in the brightness and saturation of the key color was not an effective conditional cue in a single reversal paradigm, but that the houselight cue was effective, and they rejected the possibility that the houselight exerts effects by altering these properties of the key color. This is an unfavorable result for the bidirectional occasion-setting interpretation of the complex discrimination demonstrated here. Therefore, hierarchical control is the most plausible account of the successful performance in the present study.

In relation to this point, it is worthwhile to note the function of the contextual cue of the houselight. In the present study, the condition of the houselight-on (light) or off (dark)-controlled the F-P and the F-N discriminations, in which the feature was supposed to set the occasion for, or modulate, the target-US relationship. Several recent studies, however, have suggested that the context itself can act as an occasion setter (Bouton \& Swartzentruber, 1986; Grahame, Hallam, Geier, \& Miller, 1990; Rescorla, Durlach, \& Grau, 1985; Swartzentruber, 1991; Swartzentruber \& Bouton, 1988; see also Honey, Willis, \& Hall, 1990). If the function of the context in the present study was the same as that of the ordinary occasion setter and if the feature also functions as the occasion setter, then the arranged contingency means "higher order occasion setting" (Arnold et al., 1991).

Three birds that were trained on the F-P discrimination in the light context produced some pecks to the unlit key during the feature presentation and the gap. Although the possibility that they used these pecks as an additional feature cue for the discrimination cannot be completely excluded, the data pose problems for this possibility. First, the rate of responding during the feature presentation was not correlated with the discrimination performance. Second, the rate of pecks during the gap was not a simple increasing function of the gap duration. Third, some birds showed good performance without these pecks.

It is possible that the birds engaged in some undetected behavior during the feature presentation and the gap of the F-P context, and that they used this behavior as a cue to responding to the forthcoming target. It is also possi- 
ble that they engaged in another behavior during these periods of the F-N context and used it as a cue for nonresponding to the target.

The birds for which the light context indicated the F-P contingency and the dark context indicated the F-N contingency learned the discriminations more easily than did the birds for which the former indicated the F-N contingency and the latter indicated the F-P contingency. This fact might indicate that the former birds engaged in these behaviors with ease but that the latter had difficulty in engaging in these behaviors. For example, the birds might approach the key during the feature presentation and the gap in the F-P context and use this behavior as a cue to responding to the target. And they also might engage in some nondirectional behavior, such as crouching, during the corresponding periods of the F-N context and use this behavior as a cue to nonresponding to the target. It is plausible that the acquisition of the former behavior in the light context and the latter behavior in the dark context is easier than the reverse combination.

But even if this was the case, the following questions would remain unanswered. What kinds of behaviors were acquired by the birds trained in the disadvantageous condition: the F-P discrimination in the dark context and the F-N discrimination in the light context? And why was the cuing behavior produced in the F-P discrimination less susceptible to the effects of the temporal gap than was the behavior produced in the $\mathrm{F}-\mathrm{N}$ discrimination?

\section{REFERENCES}

Arnold, H. M., Grahame, N. J., \& Miller, R. R. (1991). Higher order occasion setting. Animal Learning \& Behavior, 19, 58-64.

Bellingham, W. P., \& GilleTte, K. A. (1981). Spontaneous configuring to a tone-light compound using appetitive training. Learning \& Motivation, 12, 420-434.

Bellingham, W. P., Gillette-Bellingham, K., \& Kehoe, E. J. (1985). Summation and configuration in patterning schedules with the rat and rabbit. Animal Leaming \& Behavior, 13, 152-164.

Berryman, R., Cumming, W. W., \& Nevin, J. A. (1963). Acquisition of delayed matching in the pigeon. Journal of the Experimental Analysis of Behavior, 6, 101-107.

BLough, D. S. (1959). Delayed matching in the pigeon. Journal of the Experimental Analysis of Behavior, 2, 151-160.

Bouton, M. E., \& Swartzentruber, D. (1986). Analysis of the associative and occasion-setting properties of contexts participating in a Pavlovian discrimination. Journal of Experimental Psychology: Animal Behavior Processes, 12, 333-350.

Colwill, R. M., \& Rescorla, R. A. (1986). Associative structures in instrumental learning. In G. H. Bower (Eds.), The psychology of learning and motivation (pp. 55-104). New York: Academic Press.

Cumming, W. W., \& Berryman, R. (1965). The complex discriminated operant: Studies of matching-to-sample and related problems. In D. I. Mostofsky (Ed.), Stimulus generalization (pp. 284-330). Stanford, CA: Stanford University Press.

Davidson, T. L., Aparicio, J., \& Rescorla, R. A. (1988). Transfer between Pavlovian facilitators and instrumental discriminative stimuli. Animal Learning \& Behavior, 16, 285-291.

Grahame, N. J., Hallam, S. C., Geier, L., \& Miller, R. R. (1990). Context as an occasion setter following either CS acquisition and extinction or CS acquisition alone. Learning \& Motivation, 21, 237-265.

Holland, P. C. (1983). Occasion setting in Pavlovian feature positive discriminations. In M. L. Commons, R. J. Herrnstein, \& A. R. Wagner (Eds.), Quantitative analyses of behavior: Discrimination processes (Vol. 4, pp. 183-206). New York: Ballinger.

Holland, P. C. (1985). The nature of conditioned inhibition in serial and simultaneous feature negative discriminations. In R. R. Miller \& N. E. Spear (Eds.), Information processing in animals: Conditioned inhibition (pp. 267-297). Hillsdale, NJ: Erlbaum.

Holland, P. C., \& Block, H. (1983). Evidence for a unique cue in positive patterning. Bulletin of the Psychonomic Society, 21, 297-300.

Honey, R. C., Willis, A., \& Hall, G. (1990). Context specificity in pigeon autoshaping. Learning \& Motivation, 21, 125-136.

Kehoe, E. J., \& Gormezano, L. (1980). Configuration and combination laws in conditioning with compound stimuli. Psychological Bulletin, 87, 351-378.

Looney, T. A., Cohen, L. R., Brady, J. H., \& Cohen, P. S. (1977). Conditional discrimination performance by pigeons on a responseindependent procedure. Journal of the Experimental Analysis of Behavior, 27, 363-370.

LOONEY, T. A., \& GRIFFIN, R. W. (1978). A sequential feature-positive effect using tone as the distinguishing feature in an autoshaping procedure. Animal Learning \& Behavior, 6, 401-405.

MACKAY, H. A. (1991). Conditional stimulus control. In I. H. Iversen \& K. A. Lattal (Eds.), Experimental analysis of behavior: Part 1 (pp. 301-350). Amsterdam: Elsevier.

MOORE, G. H., \& WALLIS, W. A. (1943). Time series significance tests based on signs of differences. Journal of the American Statistical Association, 38, 153-164.

NAKAJIMA, S. (1992). The effect of temporal relationship of stimulus compound on ambiguous discrimination in the pigeon's autoshaping. Behavioural Processes, 27, 65-74.

NakaJima, S. (1993). Asymmetrical effect of a temporal gap between feature and target stimuli on Pavlovian serial feature-positive and feature-negative discriminations. Learning \& Motivation, 24, 255-265.

NeviN, J. A., \& LiEBOLD, K. (1966). Stimulus control of matching and oddity in a pigeon. Psychonomic Science, 5, 351-352.

PARKer, B. K., Serdikoff, S. L., Kaminski, B. J., \& Critchfield, T. S. (1991). Stimulus control of Pavlovian facilitation. Journal of the Experimental Analysis of Behavior, 55, 275-286.

Pearce, J. M., \& Wilson, P. N. (1990a). Configural associations in discrimination learning. Journal of Experimental Psychology: Animal Behavior Processes, 16, 250-261.

Pearce, J. M., \& Wilson, P. N. (1990b). Feature-positive discrimination learning. Journal of Experimental Psychology: Animal Behavior Processes, 16, 315-325.

Preston, G. C., Dickinson, A., \& Mackintosh, N. J. (1986). Contextual conditional discriminations. Quarterly Journal of Experimental Psychology, 38B, 212-237.

ResCorLA, R. A. (1973). Evidence for "unique stimulus" account of configural conditioning. Journal of Comparative \& Physiological Psychology, 85, 331-338.

Rescorla, R. A. (1985). Conditioned inhibition and facilitation. In R. R. Miller \& N. E. Spear (Eds.), Information processing in animals: Conditioned inhibition (pp. 299-326). Hillsdale, NJ: Erlbaum.

ResCoRLA, R. A. (1987). A Pavlovian analysis of goal-directed behavior. American Psychologist, 42, 119-129.

Rescorla, R. A. (1991a). Combinations of modulators trained with the same and different target stimuli. Animal Learning \& Behavior, $19,355-360$.

RESCORLA, R. A. (1991b). Separate reinforcement can enhance the effectiveness of modulators. Journal of Experimental Psychology: Animal Behavior Processes, 17, 259-269.

Rescorla, R. A., Durlach, P. J., \& Grau, J. W. (1985). Contextual learning in Pavlovian conditioning. In P. D. Balsam \& A. Tomie (Eds.), Context and learning (pp. 23-56). Hillsdale, NJ: Erlbaum.

Rescorla, R. A., Grau, J. W., \& Durlach, P. J. (1985). Analysis of the unique cue in configural discriminations. Joumal of Experimental Psychology: Animal Behavior Processes, 11, 356-366.

SAAVEDRA, M. A. (1975). Pavlovian compound conditioning in the rabbit. Learning \& Motivation, 6, 314-326. 
Sidman, M. (1986). Functional analysis of emergent verbal classes. In T. Thompson \& M. D. Zeiler (Eds.), Analysis and integration of behavioral units (pp. 213-245). Hillsdale, NJ: Erlbaum.

SWARTZENTRUBER, D. (1991). Blocking between occasion setters and contextual stimuli. Journal of Experimental Psychology: Animal Behavior Processes, 17, 163-173.

SWartzentruber, D., Bouton, M. E. (1988). Transfer of positive contextual control across different conditioned stimuli. Bulletin of the Psychonomic Society, 26, 569-572.

Thomas, D. R., Cook, S. C., \& Terrons, J. P. (1990). Conditional discrimination learning by pigeons: The role of simultaneous versus successive stimulus presentations. Journal of Experimental Psychology: Animal Behavior Processes, 16, 390-401.

Thomas, D. R., \& CuRRan, P. J. (1988). The role of response directedness in discriminative and conditional stimulus control. Bulletin of the Psychonomic Society, 26, 378-380.

Thomas, D. R., Curran, P. J., \& Russell, R. J. (1988). Factors affecting conditional discrimination learning by pigeons: II. Physical and temporal characteristics of stimuli. Animal Learning \& Behavior, 16, 468-476.
Thomas, D. R., \& GoldBerg, H. (1985). Conditional discrimination learning by pigeons: The role of training paradigms. Bulletin of the Psychonomic Society, 23, 256-258.

Thomas, D. R., McKelvie, A. R., \& MaH, W. L. (1985). Context as a conditional cue in operant discrimination reversal learning. Journal of Experimental Psychology: Animal Behavior Processes, 11, 317-330.

ThomAs, D. R., \& SCHMIDT, E. K. (1989). Does conditional discrimination learning by pigeons necessarily involve hierarchical relationships? Journal of the Experimental Analysis of Behavior, 52, 249-260.

WhIt low, J. W., JR., \& WAGNER, A. R. (1972). Negative patterning in classical conditioning: Summation of response tendencies to isolable and configural components. Psychonomic Science, 27, 299-301.

Wilson, P. N., \& PeArCe, J. M. (1992). A configural analysis for feature-negative discrimination learning. Joumal of Experimental $P_{s y-}$ chology: Animal Behavior Processes, 18, 265-272.

(Manuscript received November 19, 1992; revision accepted for publication June 20, 1993.) 